\title{
Investigation of diffusion behavior of carburized sheet metal in hot stamping
}

\author{
Alexander Horn ${ }^{*}$ and Marion Merklein \\ Institute of Manufacturing Technology, Friedrich-Alexander-Universität Erlangen-Nürnberg, Egerlandstraße 13, 91058 Erlangen, \\ Germany
}

Received: 4 February 2019 / Accepted: 20 May 2019

\begin{abstract}
Today, manufacturing of structural car body parts faces several challenges, like forming accuracy, passenger safety and lightweight design. One possibility to fulfill these partially rivalling demands is the application of hot stamped components. The combination of hot forming and in-die quenching reduces not only springback, but also results in tensile strengths of more than $1500 \mathrm{MPa}$. Besides conventional hot stamping, the process can be adapted to manufacture parts with tailored properties. One of the biggest issues of these state-ofthe-art processes is the formation of extensive transition zones due to heat transfer. A promising approach to adjust the mechanical properties with a minimized transition zone is tailored carburization of sheet metal. Therefore, the parts are locally coated with graphite, heat treated and subsequently quenched. In this work, the time variant process of carbon diffusion is investigated. Sheets with two different thicknesses are carburized and quenched. The resulting mechanical properties are analyzed using uniaxial tensile tests and microhardness measurements. On this basis, a process window is identified. Furthermore, the applicability of EDX and WDX analysis for the measurement of carbon concentration is investigated within this work.
\end{abstract}

Keywords: Hot stamping / heat treatment / carburization

\section{Introduction}

Ecological aspects as well as increasing safety standards are two reasons for growing importance of lightweight construction in automotive industry [1]. There are different strategies to improve lightweight design in today's manufacturing of structural car body parts. One of them is the substitution of commonly used steel grades by either light-weight materials such as aluminum or materials with higher strength [2]. With ultra-high-strength steels, it is possible to reduce sheet thickness and therefore component weight. Since high-strength materials have only limited formability and high-process forces are required, temperature-assisted forming processes are necessary [3]. Hot stamping of ultra-high-strength materials has developed to a state-of-the-art process for manufacturing lightweight, but safety-relevant components.

There are two different process routes in hot stamping. In direct hot stamping, the sheets are austenitized, transferred to the press and then subsequently formed and in-die quenched. Tensile strength of up to $1500 \mathrm{MPa}$ for the commonly used boron manganese steel $22 \mathrm{MnB} 5$ can be achieved. These high strengths are a result of a fully

\footnotetext{
* e-mail: alexander.horn@fau.de
}

martensitic structure which is developed when a cooling rate of at least $27 \mathrm{~K} / \mathrm{s}$ is ensured during in-die quenching and forming [4]. Contrary to direct hot stamping, nearly complete preforming is done before austenitization in the indirect hot stamping process. The parts are quenched and calibrated in the press subsequently to the heat treatment [5]. An overview of the process steps in direct and indirect hot stamping can be seen in Figure 1.

Since decarburization and oxidation occur during austenitization, only coated sheet material is used for hot stamping. In direct hot stamping, Al-Si coatings are commonly used [7]. Due to the limited formability of Al-Si at room temperature, other coatings, such as zinc, are preferred in indirect hot forming [4]. Furthermore, Zncoatings offer cathodic corrosion protection [8].

One challenge of hot stamped components is a low residual elongation. Especially, in crash relevant structures, high energy absorbance is desired. An example for this are b-pillars, where the bottom of the part should have increased ductility for better energy absorbance, while the upper part should retain its structural integrity for passenger safety. By adapting the conventional hot stamping process, it is possible to manually adjust the resulting mechanical properties. Strategies for tailoring of mechanical properties in hot stamping are partial hot stamping, partial austenitization, annealing and tailored 
a)
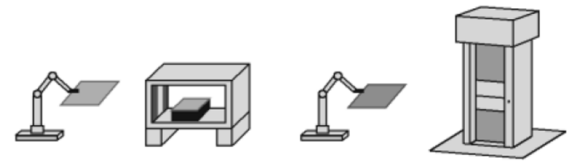

b)
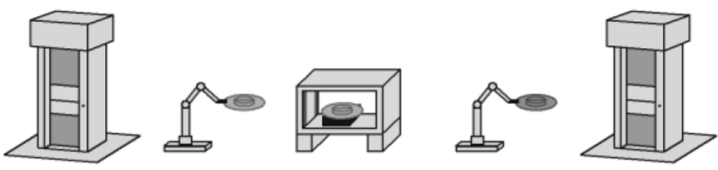

Transfer

\section{Preforming Austenitization}

Transfer Forming and in-die quenching

Fig. 1. Overview of the process steps in direct (a) and indirect (b) hot stamping according to [6].

products. By preventing a full austenitization of particular areas, or decreasing the heat transfer between tool and sheet below the critical value, it is possible to retain the original ferritic-pearlitic microstructure besides the martensitic structure [9]. One challenge of these state-of-theart process variants is the formation of a transition zone due to heat transfer between areas of different temperatures. According to Feuser [10], manufacturing of parts with a transition zone less than $30 \mathrm{~mm}$ is not feasible.

A method for minimizing this transition zone, while still being able to adjust the mechanical properties, is tailored carburization [11]. In this process, the sheet metal is locally coated with graphite and subsequently carburized [12]. Areas where carburization is not desired are masked with boron-nitride. During the heat treatment in the oven at elevated temperatures, the carbon atoms diffuse into the base material. The locally increased carbon content results in higher strength in these areas after quenching. Existing process knowledge from case hardening cannot be transferred directly due to different dimensions and objectives. Since carburization is a time variant process and depends on temperature, relevant process parameters have to be analyzed. Aim of this work is to investigate the influence of sheet thickness and several heat treatment parameters on mechanical properties of carburized samples, such as tensile strength and Vickers hardness. Depending on these influencing factors, a process window for carburization of sheet metal will be identified within this work. This will be the basis for the application of tailored carburization. Since the mechanical properties are mainly influenced by the carbon content, a suitable measurement method for the analysis of carbon distribution has to be identified as well. For this purpose, the applicability of energy- and wavelength-dispersive X-ray spectroscopy for the quantification of carbon concentration is investigated.

\section{Material and methodology}

A hot rolled, uncoated complex phase steel CP-W 800 is used in this work. The investigated sheet thicknesses are $t_{01}=1.6 \mathrm{~mm}$ and $t_{02}=2.5 \mathrm{~mm}$. Compared to conventional hot stamping steel $22 \mathrm{MnB} 5, \mathrm{CP}-\mathrm{W}^{\circledR} 800$ has a lower
Table 1. Chemical composition of CP-W $\mathrm{W}^{\circledR} 800$ in wt.\% [13].

\begin{tabular}{lllll}
\hline C max. & Si max. & Mn max. & P max. & S max. \\
\hline 0.14 & 1.00 & 2.20 & 0.080 & 0.015 \\
Al total & $\mathrm{Ti}+$ Nb max. & Cr + Mo max. & V max. & B max. \\
$0.015-2.0$ & 0.25 & 1.00 & 0.20 & 0.005 \\
\hline
\end{tabular}

Table 2. Investigated influencing factors.

\begin{tabular}{ll}
\hline Investigated parameter & Variation \\
\hline Sheet thickness $t_{0}$ & $1.6 \mathrm{~mm}, 2.5 \mathrm{~mm}$ \\
Heat treatment temperature $T_{\text {oven }}$ & $900^{\circ} \mathrm{C}, 950{ }^{\circ} \mathrm{C}$ \\
Holding time $t_{\text {hold }}$ & $5 \mathrm{~min}, 1 \mathrm{~h}, 3 \mathrm{~h}, 6 \mathrm{~h}$ \\
\hline
\end{tabular}

carbon content. The difference between both alloys is 0.11 wt.\%. This enables the possibility of further carburization. The chemical composition of $\mathrm{CP}-\mathrm{W}^{\circledR} 800$ can be seen in Table 1.

The carbon source for carburization is a graphite foil of type 90/10 from KERAFOL Keramische Folien GmbH with a thickness of $0.15 \mathrm{~mm}$. The bonding between base material and graphite is realized by application of the adhesive COT Resbond 931C (Polytec PT GmbH). During air curing, the ceramic binder evaporates, so that the adhesive consists of $99 \%$ graphite after hardening. To limit oxidation and decarburization during austenitization, the specimens are wrapped into heat treatment foil with a thickness of $0.051 \mathrm{~mm}$ from Schröder Industrieöfen GmbH.

Besides the thickness of the steel sheets, heat treatment temperature and holding time are investigated as influencing factors. The different specifications are shown below in Table 2. Subsequently to the carburization in the oven, the specimens are quenched in water.

After carburization and quenching, tensile tests are conducted using a universal testing machine Zwick Z100 in combination with a digital image correlation system Aramis (GOM GmbH). Afterwards, small segments are separated from the tested samples and embedded in epoxy resin for microhardness measurements in a Fischerscope HM1000. The Vickers hardness HV 0.1 is measured on the middle plane of the samples' cross section as well as along the sheet thickness for selected samples. Afterward, carbon content of the carburized samples is measured via energy(EDX) as well as wavelength-dispersive spectroscopy (WDX).

EDX and WDX are two measurement methods for the characterization of materials. By exciting the probe with an external electron beam, an electron from the inner shell is moved to a higher energy level. Returning to the vacant slot on the lower energy level, a photon is emitted. The specific energy and wavelength of this photon are characteristic for the respective element [14]. Since several elements can be detected at the same time, EDX is a fast measurement method [15]. Compared to EDX, WDX takes 


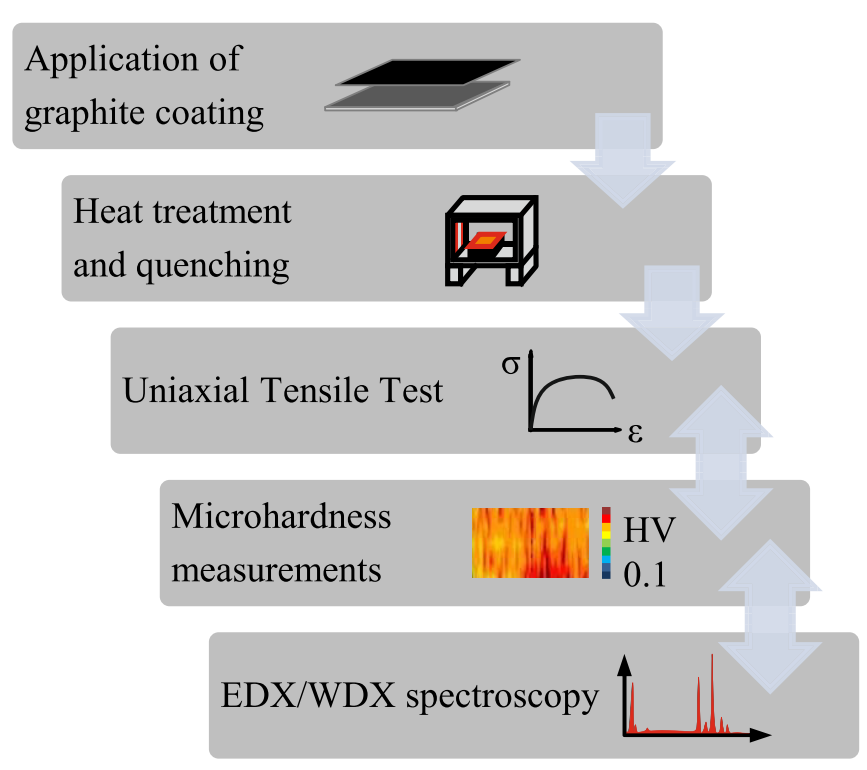

Fig. 2. Used methodology in this work.

more time, since only one element can be analyzed at the same time, but has improved accuracy because of increased energy resolution. Due to overlapping when resolution is not satisfactory, the identification of peaks in the X-ray spectrum can be challenging [16]. Furthermore, reproducibility, as well as the detection of light elements, such as nitrogen or carbon, is better with WDX [17].

In the work of Wang et al. [18] as well as in the publication of Ebrahimian and Ghasemi Banadkouki [19], EDX was used for comparative analysis of carbon distribution. Since detection time is superior, the applicability of EDX for the qualitative analysis of carbon content of carburized samples is investigated first. After that, wavelength-dispersive X-ray spectroscopy is performed as well. The measurements are carried out with a scanning electron microscope of type ZEISS MERLIN GEMINI II, which is equipped with an OXFORD X-Max ${ }^{\mathrm{N}}$ Silicon Drift Detector 50 for EDX analysis. Furthermore, the SEM system has an INCA WAVE spectrometer for WDX analysis. The results from carbon analysis are correlated with mechanical properties from tensile tests and microhardness measurements. An overview of the used methodology is given in Figure 2.

\section{Results}

\subsection{Tensile strength}

Figures 3 and 4 show the resulting tensile strength after carburization at $900^{\circ} \mathrm{C}$ and $950^{\circ} \mathrm{C}$ in comparison with uncoated specimens. It can be seen in Figure 3, that an increase in tensile strength by carburization is achievable. After a heat treatment of five minutes at $900{ }^{\circ} \mathrm{C}$, the values are below the initial state, with the best results for a sheet thickness of $1.6 \mathrm{~mm}$. After one hour, the tensile strength of the specimens with a thickness of $1.6 \mathrm{~mm}$ is slightly increased to $(787.2 \pm 4.9) \mathrm{MPa}$. For the samples with

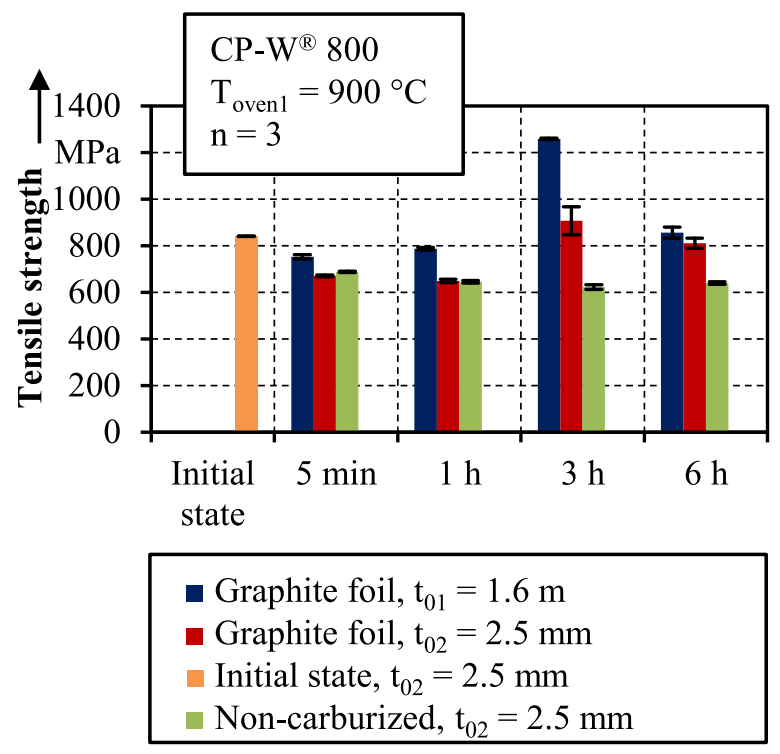

Fig. 3. Tensile strength of coated and uncoated specimens after a heat treatment at $900^{\circ} \mathrm{C}$.

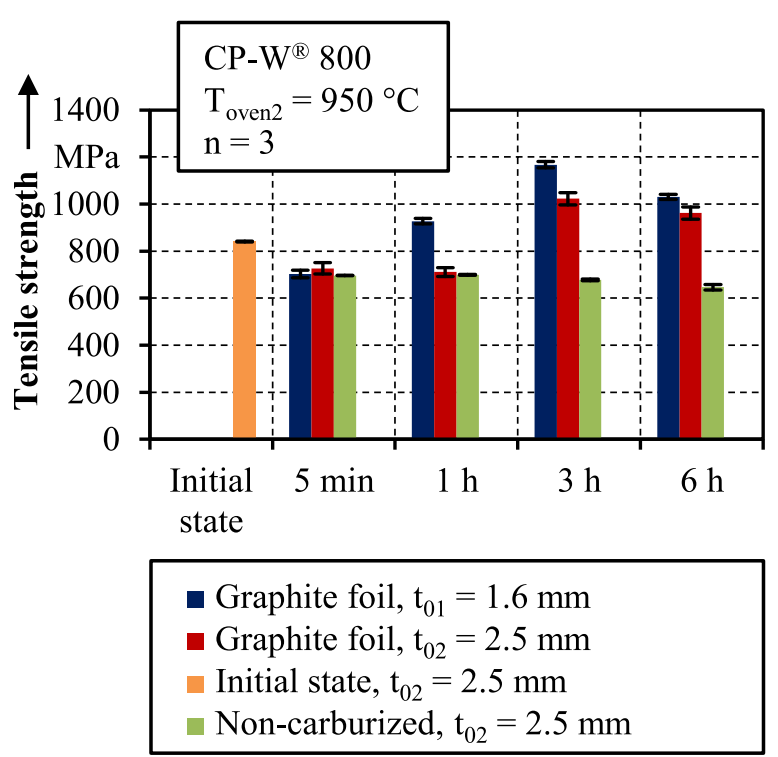

Fig. 4. Tensile strength of coated and uncoated specimens after a heat treatment at $950^{\circ} \mathrm{C}$.

$t_{02}=2.5 \mathrm{~mm}$, the values are decreased, independent of potential carburization.

After three hours of heat treatment, major differences can be seen. While tensile strength is further decreased for specimens without graphite coating, carburization results in a significant increase in tensile strength. The maximum of tensile strength of $(1258.9 \pm 2.0) \mathrm{MPa}$ is reached for specimens with a sheet thickness of $1.6 \mathrm{~mm}$. This is significantly higher compared to the initial state with $(840.4 \pm 1.0) \mathrm{MPa}$ and the specimens with $t_{02}=2.5 \mathrm{~mm}$. Doubling the dwell time to six hours results in a decrease of tensile strength of carburized samples to $(855.4 \pm 23.5) \mathrm{MPa}$ 
for $t_{01}=1.6 \mathrm{~mm}$ and $(809.9 \pm 21.8) \mathrm{MPa}$ for $t_{02}=2.5 \mathrm{~mm}$, respectively. The tensile strength of specimens without graphite coating remains on the same level as before.

Figure 4 shows the resulting tensile strength after a heat treatment at $950^{\circ} \mathrm{C}$ and subsequent quenching. The trend of tensile strength is similar to a carburization temperature of $900{ }^{\circ} \mathrm{C}$, with a difference only after five minutes of heat treatment, where the carburized samples with a sheet thickness of $2.5 \mathrm{~mm}$ show the highest tensile strength with (726.7 \pm 25.0$) \mathrm{MPa}$. Considering the standard devitiation, the difference to samples with a thickness of $1.6 \mathrm{~mm}$ is not significant. Except for the samples heat treated for five minutes at $900{ }^{\circ} \mathrm{C}$, the investigated specimens with a sheet thickness of $1.6 \mathrm{~mm}$ achieve higher values of tensile strength compared to those with a thickness of $2.5 \mathrm{~mm}$.

Regarding the absolute values of tensile strength of both carburization temperatures, further differences are visible. A heat treatment at $950^{\circ} \mathrm{C}$ results in higher tensile strength than carburization at $900^{\circ} \mathrm{C}$. An exception can be seen for the maximum of $T_{\text {oven } 2}=950{ }^{\circ} \mathrm{C}$ with $(1167.2 \pm 12.8) \mathrm{MPa}$ for three hours and $t_{01}=1.6 \mathrm{~mm}$. This is about $90 \mathrm{MPa}$ lower compared to the maximum of $T_{\text {oven } 1}=900^{\circ} \mathrm{C}$.

Since the diffusion of carbon atoms is significantly improved at higher temperatures [20], a carburization temperature of $950^{\circ} \mathrm{C}$ leads to an increased carbon concentration, which results in higher tensile strength compared to $900^{\circ} \mathrm{C}$. Furthermore, the mechanical properties are influenced by grain growth. Merklein and Svec [21] investigated the influence of different austenitization parameters on mechanical properties of CP-800 after hot stamping. In this context, they analyzed the grain size in dependency of prior heat treatment parameters. It was shown that a temperature of $950^{\circ} \mathrm{C}$ leads to significant grain growth already after one hour, which is a possible reason why the overall maximum of tensile strength is achieved for a carburization temperature of $900{ }^{\circ} \mathrm{C}$. Furthermore, the investigations of Merklein and Svec revealed that grain growth exists for $900^{\circ} \mathrm{C}$ as well. Since it is less distinct than for $950^{\circ} \mathrm{C}$, it is noticeable only for enhanced carburization times. This explains the decrease in tensile strength for a carburization time of six hours at $900^{\circ} \mathrm{C}$ compared to three hours at the same temperature. Since the carbon atoms diffuse from the graphite steel interface into the substrate material, increasing the sheet thickness enhances the diffusion path as well. As a result, the concentration of carbon atoms in the mid-section of thicker sheets is decreased. These differences in carbon distribution are the reason for higher tensile strength of sheets with a thickness of $1.6 \mathrm{~mm}$.

\subsection{Vickers hardness}

Figure 5 shows the Vickers hardness HV 0.1 after carburization between five minutes and six hours at $900{ }^{\circ} \mathrm{C}$ and $950{ }^{\circ} \mathrm{C}$ in comparison with the initial state before heat treatment. The measurements are conducted in the middle plane of the samples' cross section. Furthermore, the distribution of Vickers hardness HV 0.1 along the sheet thickness is shown in Figure 6 for selected samples with high tensile strength as well as high Vickers hardness.

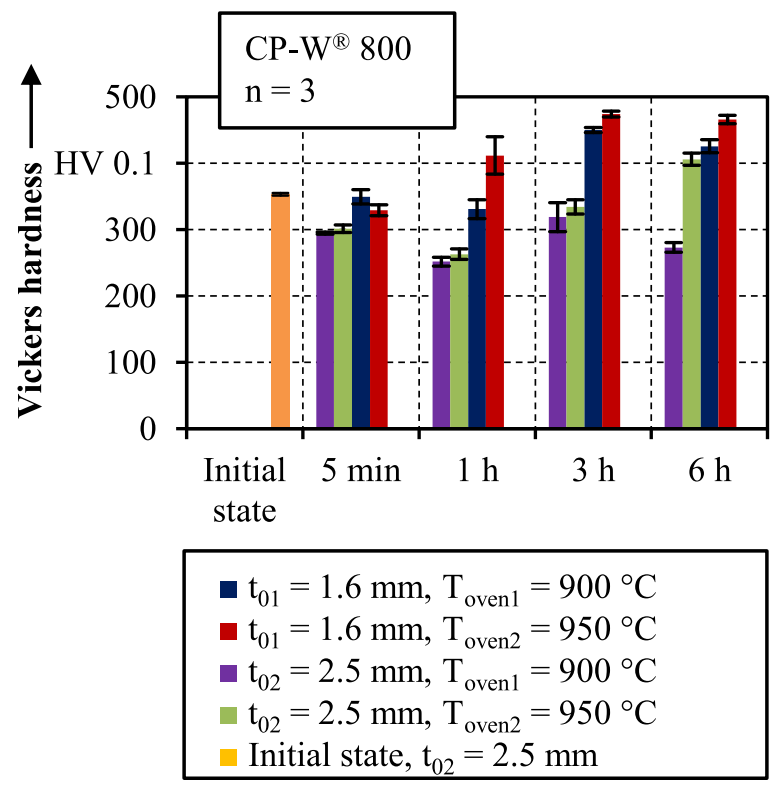

Fig. 5. Vickers hardness of carburized samples in comparison with initial state.

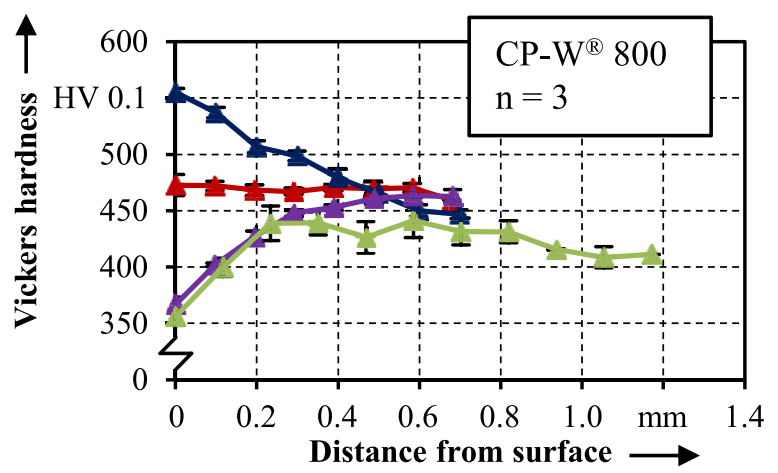

$$
\begin{aligned}
& \square \mathrm{t}_{01}=1.6 \mathrm{~mm}, \mathrm{~T}_{\text {oven } 1}=900^{\circ} \mathrm{C}, \mathrm{t}_{\text {hold } 3}=3 \mathrm{~h} \\
& \square \mathrm{t}_{01}=1.6 \mathrm{~mm}, \mathrm{~T}_{\text {oven } 2}=950^{\circ} \mathrm{C}, \mathrm{t}_{\text {hold } 3}=3 \mathrm{~h} \\
& \square \mathrm{t}_{01}=1.6 \mathrm{~mm}, \mathrm{~T}_{\text {oven } 2}=950^{\circ} \mathrm{C}, \mathrm{t}_{\text {hold } 4}=6 \mathrm{~h} \\
& \square \mathrm{t}_{02}=2.5 \mathrm{~mm}, \mathrm{~T}_{\text {oven } 2}=950^{\circ} \mathrm{C}, \mathrm{t}_{\text {hold } 4}=6 \mathrm{~h}
\end{aligned}
$$

Fig. 6. Distribution of Vickers hardness along the sheet thickness of selected samples with a sheet thickness of 1.6 and $2.5 \mathrm{~mm}$ after carburization of three and six hours at 900 and $950^{\circ} \mathrm{C}$.

Figure 5 corresponds well with the findings from tensile testing. Carburization shorter than three hours results in lower Vickers hardness compared to the initial state with $(353.4 \pm 2.1)$ HV 0.1 . The only exception is a heat treatment of one hour at $950^{\circ} \mathrm{C}$, as already seen from tensile testing. For a sheet thickness of $2.5 \mathrm{~mm}$, a significant improvement of Vickers hardness up to $(406.2 \pm 9.4)$ HV 0.1 can be achieved only for six hours of carburization at a temperature of $950^{\circ} \mathrm{C}$. Since thicker sheet material leads to an enhanced diffusion path, an increase in Vickers 


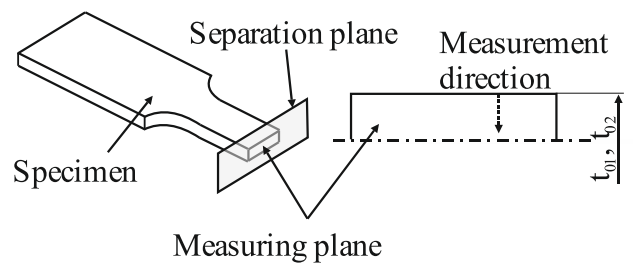

Fig. 7. Location of measuring points for the distribution of Vickers hardness along the sheet thickness.

hardness is reached after longer carburization times compared to $t_{01}=1.6 \mathrm{~mm}$. Again, the best results can be seen for a sheet thickness of $1.6 \mathrm{~mm}$. The maximum is (474.4 \pm 4.2$) \mathrm{HV} 0.1$ for carburization parameters of three hours and $950^{\circ} \mathrm{C}$. After six hours, the hardness is only around $8.5 \mathrm{HV} 0.1$ below the maximum. For $900^{\circ} \mathrm{C}$, the difference between three and six hours is $24.6 \mathrm{HV} 0.1$ with $(450.4 \pm 3.6) \mathrm{HV} 0.1$ as the higher value after three hours.

The analysis of Vickers hardness shows the same tendencies as the tensile strengths. A higher heat treatment temperature leads to an increased diffusion coefficient which results in elevated hardness values. Since the varying carbon concentration along the sheet thickness involves a change in mechanical properties as well, it is insufficient to only analyze the Vickers hardness in the mid-section. Therefore, it is necessary to investigate the distribution of Vickers hardness for further correlations.

The location of the measuring points is shown in Figure 7 , while the resulting values can be seen in Figure 6 . The distance between the measuring points is $(97.8 \pm 0.4) \mu \mathrm{m}$ for samples with a thickness of $1.6 \mathrm{~mm}$ and $(112.0 \pm 0.02) \mu \mathrm{m}$ for specimens with a thickness of $2.5 \mathrm{~mm}$.

The influence of carburization time on the distribution of Vickers hardness can be derived from Figure 6 . After three hours at $950{ }^{\circ} \mathrm{C}$, an almost homogeneous hardness distribution with values ranging from $(459.6 \pm 0.04) \mathrm{HV} 0.1$ to $(472.7 \pm 9.5)$ HV 0.1 can be seen. By increasing heat treatment time to six hours hardness is significantly decreased near the surface. There are two possible explanations for this. One is parallel ongoing decarburization. In contrast to the conventional hot stamping process, where only sheet material with protective coating against scale formation such as AlSi is used, the complex phase steel is uncoated in the as-delivered condition. In order to prevent the graphite layer for carburization from oxidation, additional heat treatment foil is used. This reduces decarburization of the sheets during the holding time to a minimum. The second explanatory approach is elevated carbon content. With rising carbon concentration, martensite finish temperature $M_{\mathrm{F}}$ decreases. As soon as the carbon content exceeds $0.5 \mathrm{wt} . \%, M_{\mathrm{F}}$ reaches below room temperature [22]. Since carburization results in a gradient of carbon concentration along the sheet thickness, $M_{\mathrm{F}}$ varies as well. As long as no subzero cooling is applied, this results in different amounts of retained austenite which leads to decreased hardness below the surface. This behavior can be seen in Figure 6 , where samples carburized for six hours at $950^{\circ} \mathrm{C}$ show Vickers hardness of $(366.6 \pm 6.6) \mathrm{HV} 0.1$ for a thickness of $1.6 \mathrm{~mm}$ and $(356.0 \pm 7.8)$ HV 0.1 for samples with $t_{02}=2.5 \mathrm{~mm}$, respectively. With growing distance from the surface, carbon level is expected to decrease, which leads to a higher amount of martensite and therefore increasing hardness. From the surface to a distance of around $0.2 \mathrm{~mm}$, samples carburized for six hours at $950{ }^{\circ} \mathrm{C}$ show high accordance in their hardness, independent of the sheet thickness. From there to the midsection, increased Vickers hardness can be seen for samples with a thickness of $1.6 \mathrm{~mm}$. Due to the lower thickness, diffusion of carbon atoms has proceeded into deeper regions of the material with regard to the overall thickness. Furthermore, the distribution of hardness is more homogeneous in the sheet plane as well. This can be seen by increased standard deviation for specimens with a thickness of $2.5 \mathrm{~mm}$.

The tensile tests revealed that the maximum of tensile strength is achieved for carburization of three hours at $900^{\circ} \mathrm{C}$. Contrary to that, the maximum of Vickers hardness in the mid-section was reached for a heat treatment temperature of $950^{\circ} \mathrm{C}$. An explanation for this difference can be derived from Figure 6. As already mentioned, after carburization of three hours at $950^{\circ} \mathrm{C}$, a very homogenous hardness distribution is achieved. In contrast to that, a heat treatment temperature of $900{ }^{\circ} \mathrm{C}$ results in a hardness gradient. In the middle of these samples, Vickers hardness is around 12.6 to $20.2 \mathrm{HV} 0.1$ below the values of specimens with a heat treatment temperature of $950^{\circ} \mathrm{C}$, which was already explained with a decreased diffusion coefficient due to lower temperature. Apart from the midsection, samples carburized at $900^{\circ} \mathrm{C}$ show up to $82.3 \mathrm{HV} 0.1$ higher values for Vickers hardness. Besides retained austenite due to enhanced carbon concentrations near the surface, grain growth due to elevated temperatures is a possible explanation.

Calculating the average Vickers hardness along the sheet thickness, highest values are achieved for sheets with a thickness of $1.6 \mathrm{~mm}$ and carburization of three hours at $900^{\circ} \mathrm{C}$ with $(492.4 \pm 19.1) \mathrm{HV} 0.1$, followed by three hours at $950^{\circ} \mathrm{C}$ with $(468.7 \pm 5.3) \mathrm{HV} 0.1$ and six hours at $950^{\circ} \mathrm{C}$ with $(435.4 \pm 16.9) \mathrm{HV}$ 0.1. The lowest average Vickers hardness along the sheet thickness can be seen for samples with a thickness of $2.5 \mathrm{~mm}$ and heat treatment parameters of six hours and $950^{\circ} \mathrm{C}$ with $(419.5 \pm 16.2) \mathrm{HV}$ 0.1. This corresponds well with the results from tensile testing.

In addition to the hardness measurements, the samples were etched with Nital. Figure 8 shows the corresponding micrographs of samples with a sheet thickness of $1.6 \mathrm{~mm}$ carburized for three and six hours at $950^{\circ} \mathrm{C}$. The microstructure mainly consists of martensite. For samples carburized for six hours, the amount of light etching areas is increased. This is an indication for an increased percentage of retained austenite. In contrast to samples carburized for three hours, the occurrence of retained austenite is not limited to the edge region, but reaches further into the sheet material. With regard to a quantification of the retained austenite, further investigations are necessary, for example, electron backscatter diffraction. 

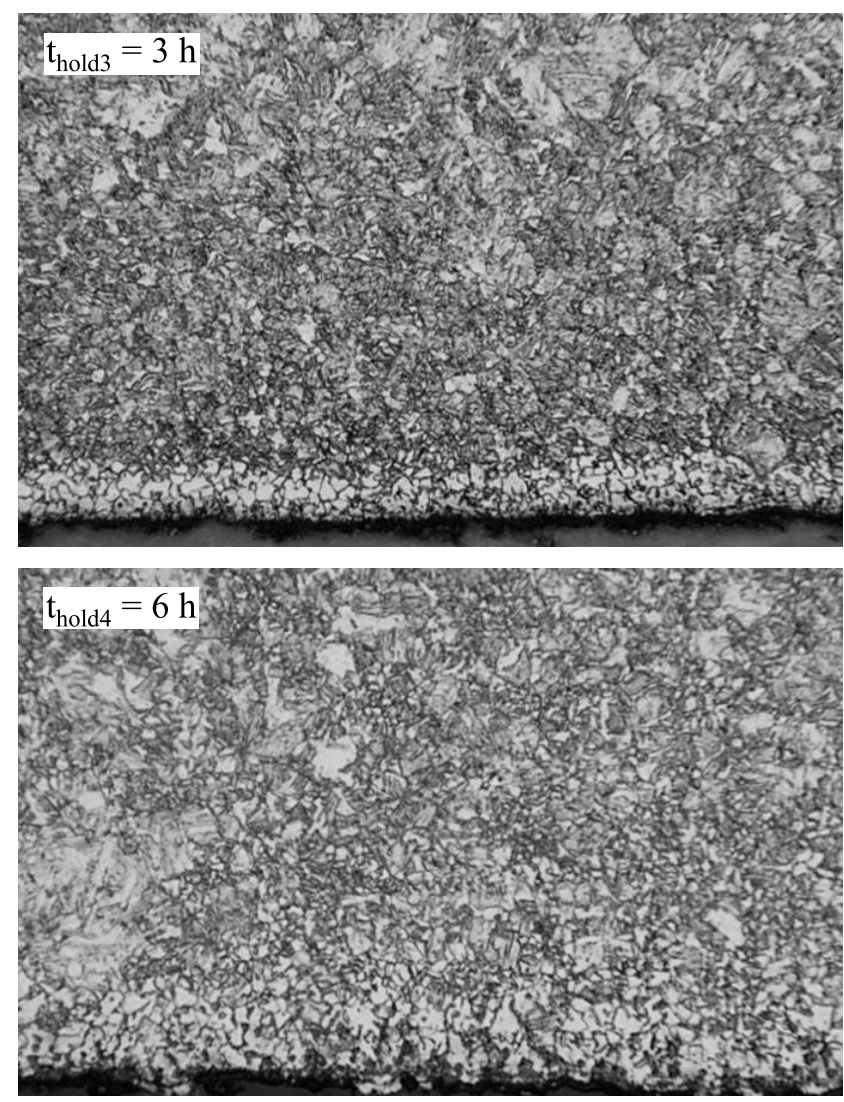

\begin{tabular}{|lll|}
\hline CP-W 800 & $3 \%$ Nital & $50 \mu \mathrm{m}$ \\
$\mathrm{t}_{01}=1.6 \mathrm{~mm}$ & $\mathrm{~T}_{\text {oven } 2}=950{ }^{\circ} \mathrm{C}$ & \\
\hline
\end{tabular}

Fig. 8. Micrograph of carburized samples.

\subsection{X-ray spectroscopy}

To correlate the mechanical properties with the carbon content, a suitable measurement method for the determination of carbon profiles has to be identified. For this purpose X-ray spectroscopy was conducted and the applicability of EDX and WDX for quantitative measurements of carbon concentration is investigated.

\subsubsection{Energy-dispersive $X$-ray analysis}

Figures 10 and 11 show the carbon content of four different samples measured with energy-dispersive X-ray spectroscopy (EDX). The carbon content of samples carburized at $900{ }^{\circ} \mathrm{C}$ is illustrated in Figure 10, while the measurement data for specimens heat treated at $950^{\circ} \mathrm{C}$ can be seen in Figure 11. The values were measured via line measurement along the sheet thickness as depicted in Figure 9. The distribution of carbon and iron content shows a clear boundary, where iron concentration rapidly increases and carbon level decreases. This corresponds to the transition of the graphite coating to the substrate material. Since there is oscillation in the signal, the measured values were averaged over a range of $100 \mu \mathrm{m}$ in a distance of 50 to

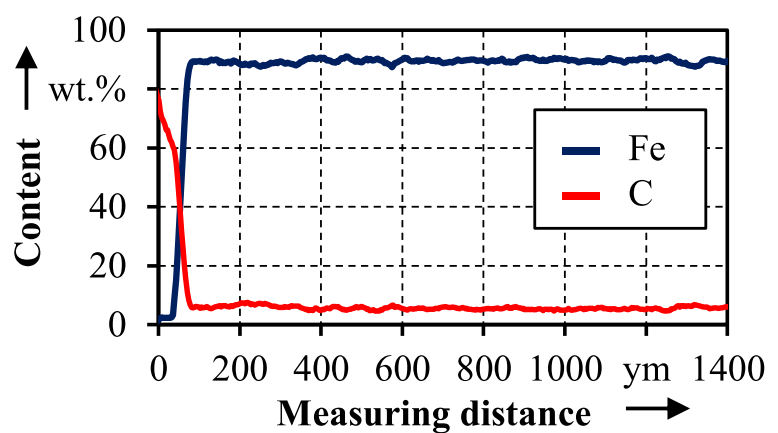

Fig. 9. Iron and carbon content of graphite-coated samples determined via EDX line measurement.

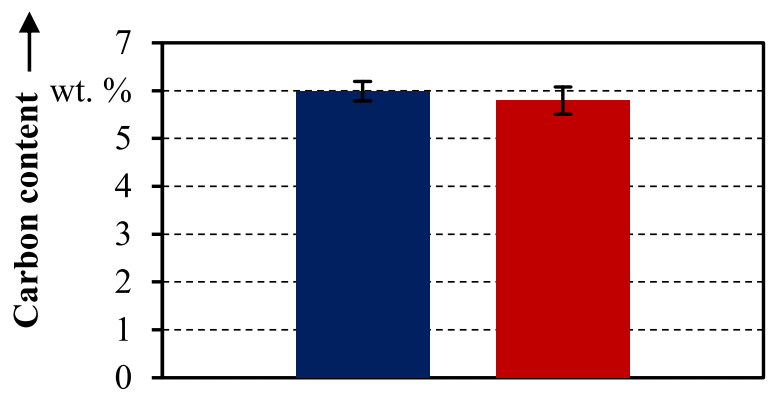

$$
\begin{aligned}
& \text { - Surface } \square \text { Mid-Section } \\
& \mathrm{t}_{01}=1.6 \mathrm{~mm}, \mathrm{~T}_{\text {oven } 1}=900{ }^{\circ} \mathrm{C}, \mathrm{t}_{\text {hold } 3}=3 \mathrm{~h} \\
& \mathrm{CP}-\mathrm{W}^{\circledR} 800, \mathrm{n}=3, \mathrm{EHT}=20 \mathrm{kV}
\end{aligned}
$$

Fig. 10. Carbon content of sample with a sheet thickness of $1.6 \mathrm{~mm}$ carburized for three hours at $900^{\circ} \mathrm{C}$ measured via EDX spectroscopy.

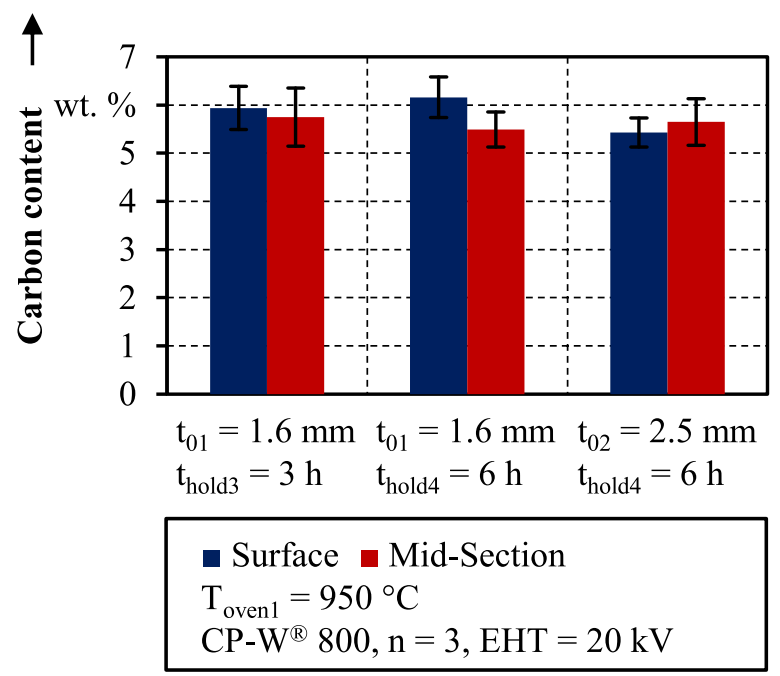

Fig. 11. Carbon content of samples carburized at $950^{\circ} \mathrm{C}$ measured via EDX spectroscopy. 

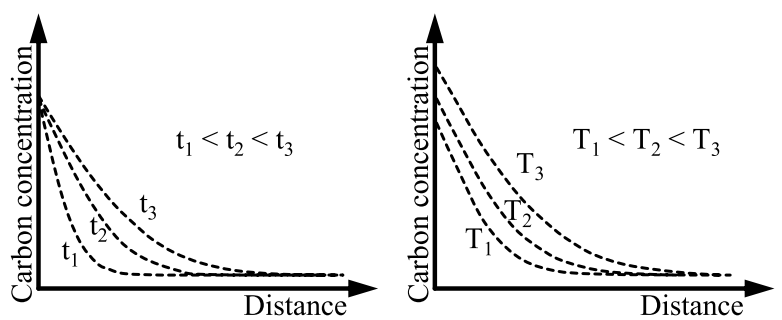

Fig. 12. Carbon profile in dependency of carburization time and temperature according to Goldstein and Moren [23].

$150 \mu \mathrm{m}$ below the surface and in the middle of the samples' cross section.

The measured carbon content ranges from $(5.79 \pm 0.29)$ wt. \% to $(5.99 \pm 0.20)$ wt.\%. This is significantly higher compared to normally achieved carbon concentrations of up to $1.25 \mathrm{wt}$.\% during carburization [23]. Typically, a surface carbon content of around $0.85 \mathrm{wt} . \%$ is desired in conventional case hardening processes [24]. A higher carbon level might result in an excessive amount of retained austenite due to a change of martensite finish temperature or in the formation of carbides [22]. Originating from the surface, the carbon content continuously declines. The exact shape of the carbon profile depends on the carburization parameters [25]. For this reason, a lower surface carbon concentration might result in insufficient hardness in the mid-section. An example for characteristic carbon profiles in dependency of carburization time and temperature is shown in Figure 12.

Comparing the carbon content near the surface and in the mid-section, the samples show the distribution of a characteristic carbon profile with lower values in the core. Considering the standard deviation, the effect is not significant. In addition to the statistical error, displayed by the standard deviation, the measurement data contains an overall absolute measurement error due to low accuracy of energy-dispersive X-ray spectroscopy on light elements such as carbon [26]. Therefore, a quantitative analysis of carbon content is not possible. Since a quantitative analysis is not feasible, a comparison of different samples amongst each other is challenging. Therefore, only the applicability of EDX for qualitative analysis of carbon content is investigated by comparing the carbon concentrations below the surface and in the mid-section to each other.

Regarding the specimens with a holding time of three hours and a thickness of $1.6 \mathrm{~mm}$, a very homogeneous distribution of carbon level can be seen. The difference between the mid-section and the surface amounts to $0.19 \mathrm{wt} . \%$ but is not significant due to standard deviation. A comparable behavior with a homogeneous hardness distribution was already shown for these samples in Figure 6. The same applies to samples with a sheet thickness of $1.6 \mathrm{~mm}$ carburized for six hours at $950^{\circ} \mathrm{C}$. With regard to standard deviation only a tendency can be indicated. In this case, the carbon content is distributed as expected, with higher values near the surface. A discrepancy can be seen for samples with a thickness of $2.5 \mathrm{~mm}$ carburized for six hours at $950^{\circ} \mathrm{C}$, where carbon level of the

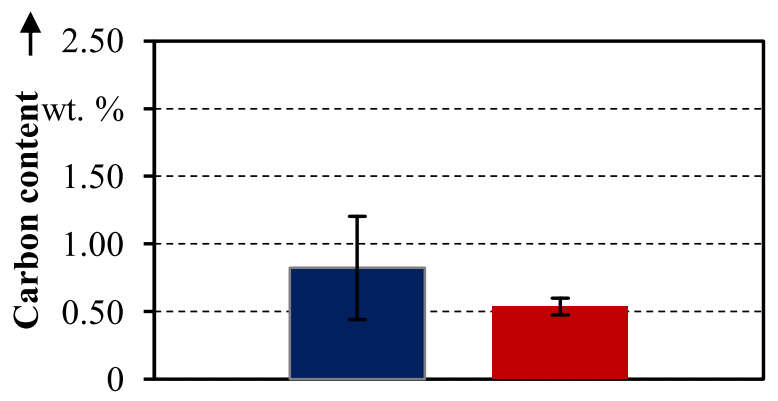

$$
\begin{aligned}
& \text { - Surface } \text { - Mid-Section } \\
& \mathrm{t}_{01}=1.6 \mathrm{~mm}, \mathrm{~T}_{\text {oven } 1}=900^{\circ} \mathrm{C}, \mathrm{t}_{\text {hold }}=3 \mathrm{~h} \\
& \mathrm{CP}-\mathrm{W}^{\circledR} 800, \mathrm{n}=3, \mathrm{EHT}=15 \mathrm{kV}
\end{aligned}
$$

Fig. 13. Carbon content of sample with a sheet thickness of $1.6 \mathrm{~mm}$ carburized for three hours at $900^{\circ} \mathrm{C}$ measured via WDX spectroscopy.

mid-section is higher than near the surface. Again, the effect is not significant due to standard deviation.

Aim of this investigation was to identify a suitable measurement method for the analysis of carbon profile after carburization. EDX spectroscopy was applied due to the possibility of detecting various elements with short measurement time. But the results revealed that energydispersive X-ray spectroscopy is not applicable in terms of quantitative analysis of carbon concentration as expected. The measured values in Figures 10 and 11 were out of the expected range derived from literature. The qualitative analysis of carbon content was partly in accordance with previous investigations, but lacked significance due to high standard deviation. This can be explained with the small differences in carbon concentration along the sheet thickness. Carbon level is expected to range between $1.25 \mathrm{wt} \%$. and the initial amount as derived from conventional carburization processes. These variations are too small to be determinable by EDX. This assumption is supported by the line measurements in Figure 9, where the boundary between graphite coating and substrate material is clearly visible. For this reason, on basis of the investigations carried out within this work, EDX is not applicable for the purpose of measuring the carbon profile. As a possible alternative, wavelength-dispersive X-ray spectroscopy (WDX) will be investigated as well.

\subsubsection{Wavelength-dispersive $X$-ray analysis}

Compared to EDX, WDX offers increased accuracy and reproducibility. Since it is more time consuming than energy-dispersive X-ray spectroscopy, only point measurements were done instead of line measurements. The carbon content was analyzed $100 \mu \mathrm{m}$ below the surface as well as in the mid-section, analogous to hardness measurements. Furthermore, due to preliminary investigations with $\mathrm{EHT}=20 \mathrm{kV}$, acceleration voltage is decreased to $15 \mathrm{kV}$, since spatial resolution improves with lower voltage [15].

Figure 13 shows the results for the samples with a sheet thickness of $1.6 \mathrm{~mm}$ carburized for three hours at $900^{\circ} \mathrm{C}$. 


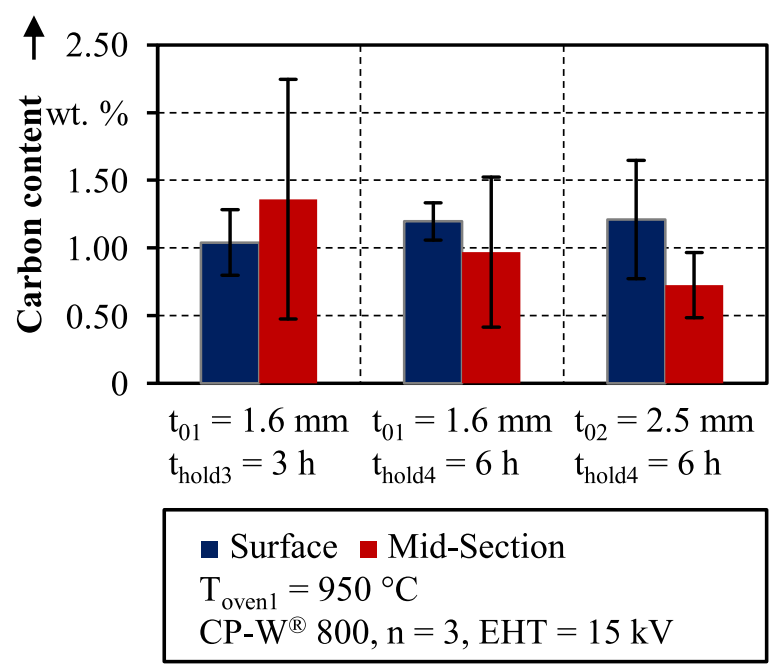

Fig. 14. Carbon content of samples carburized at $950{ }^{\circ} \mathrm{C}$ measured via EDX spectroscopy.

The carbon content is significantly lower compared to the measurements done via energy-dispersive X-ray spectroscopy, which might be traced back to increased accuracy due to improved spectral resolution [16]. The values range from $(0.54 \pm 0.06)$ wt. $\%$ in the mid-section to $(0.82 \pm 0.38)$ wt.\% near the surface, which is more realistic for carburization according to literature [24]. While this distribution of carbon content is as expected, additional data points are necessary to verify the accordance with characteristic carbon profiles as shown in Figure 12.

Figure 14 shows the carbon content of samples carburized at $950{ }^{\circ} \mathrm{C}$. Compared to samples carburized at $900^{\circ} \mathrm{C}$, an increase in heat treatment temperature of $50^{\circ} \mathrm{C}$ leads to an increase in carbon content to $(1.03 \pm 0.24) \mathrm{wt} . \%$ after three hours. Doubling the holding time to six hours, carbon content further increases to approximately $1.20 \mathrm{wt} . \%$. With respect to standard deviation, these findings correspond well to the results in Figure 6, where a reduction of Vickers hardness was explained with decreasing martensite finish temperature due to rising carbon concentration. Regarding the carbon content in the mid-section no distinct statement is possible because of high standard deviation.

In summary, carbon concentration determined via wavelength-dispersive X-ray spectroscopy revealed better accordance with values from literature in comparison with energy-dispersive X-ray spectroscopy. However, the standard deviation was still very high, which makes a quantitative measurement of carbon content challenging. The increased standard deviation can partly be traced back to single deviating values. Another influencing factor is the acceleration voltage which affects the spatial resolution of energy peaks. Since carbon is a light element with low energy peaks, further reduction of acceleration voltage might be a possible strategy to improve accuracy and reproducibility. Moreover, an alternative measurement method is necessary to validate the findings from WDX. A potential approach for spatially resolved analysis of carbon profiles is secondary ion mass spectroscopy [27].

\section{Conclusion and outlook}

The analysis of resulting mechanical properties leads to the conclusion that an applicable process window for both sheet thicknesses is limited to three hours at 900 and $950{ }^{\circ} \mathrm{C}$. An extended process window includes carburization times of up to six hours for a temperature of $950^{\circ} \mathrm{C}$. Considering an industrial application of the process, the identified process window is not feasible for production lines with cycle times of few seconds, but is an alternative for more flexible productions of high strength crash relevant parts. Moreover, it is conceivable to separate the process with direct hardening, which was applied within this work, in two steps. The adjustment of mechanical properties by a local carburization of the sheets can be done during manufacturing of the semifinished parts. The second step, the hardening, is integrated in the conventional hot stamping process as before. This is a common process sequence in case of hardening in bulk metal forming. The applicability of the identified process window for this process adaption has to be verified in future work.

On basis of the results from X-ray spectroscopy, it can be concluded that the application of EDX and WDX is challenging with the given setup in terms of quantitative carbon analysis. Consequently, further research has to focus on alternative measurement techniques and the optimization of EDX and WDX parameters for improvement of accuracy and reproducibility.

The authors would like to thank the German Research Foundation (DFG) for funding the project "Tailored Carburization: Gradierung mechanischer Eigenschaften in der Blechebene und über die Blechdicke" (DFG ME 2043/51-1).

\section{References}

1. A. Turetta, S. Bruschi, A. Ghiotti, JMPT 117 (2006) 396-400

2. K. Mori, P.F. Bariani, B.-A. Behrens, A. Brosius, S. Bruschi, T. Maeno, M. Merklein, J. Yanagimoto, CIRP Ann. 66 (2017) 755-777

3. R. Neugebauer, T. Altan, M. Geiger, M. Kleiner, A. Sterzing, CIRP Ann. 55 (2006) 793-816

4. H. Karbasian, A.E. Tekkaya, JMPT 210 (2010) 2103-2118

5. S. Bruschi, A. Ghiotti, Comprehensive materials processing, Elsevier, Amstradam, 2014, pp. 27-54

6. C. Schäffner, PhD thesis, Leibniz Universität Hannover, 2009

7. L. Pelcastre, J. Hardell, A. Rolland, B. Prakash, JMPT 228 (2016) 117-124

8. C.W. Lee, D.W. Fan, R. Sohn, S.J. Lee, R. Cooman, Metall. Mater. Trans. A 43A (2012) 5122-5127

9. M. Merklein, M. Wieland, M. Lechner, S. Bruschi, A. Ghiotti, JMPT 228 (2016) 11-24

10. P. Feuser, $\mathrm{PhD}$ thesis, Friedrich-Alexander-Universität Erlangen-Nürnberg, 2012

11. B.F. Rolfe, A. Abdollahpoor, Y. Wang, M. Pereira, H. Kong, D. Fabijanic, K. Hu, R. Han, K. Gao, A. Liu, L. Pan, Y. Bi, Z. J. Wang, Y.S. Zhang, in: Y. Zhang (Ed.), Proceedings of the $3^{\text {rd }}$ International Conference on Advanced High Strength Steel and Press Hardening, Xi'an, 2017, World Scientific, Singapore, pp. 346-351 
12. A. Horn, M. Merklein, AIP Conf. Proc. 1960 (2018) 160012

13. N.N.: Complex phase steels CP-W ${ }^{\circledR}$ and CP-K ${ }^{\circledR}$, thyssenkrupp, 2017

14. D. Shindo, T. Oikawa, Analytical electron microscopy for materials science, Springer, Japan, 2002

15. J.J. Friel, E. Lyman, Microsc. Microanal. 12 (2006) 2-25

16. A. Ul-Hamid, H.M. Tawancy, A.-R.I. Mohammed, S.S. Al-Jaroudi, N.M. Abbas, Mater. Charact. 56 (2006) 192-199

17. J.I. Goldstein, D.E. Newbury, J.R. Michael, N.W.M. Ritchie, J.H.J. Scott, D.C. Joy, Scanning electron microscopy and X-ray microanalysis, 4th edn., Springer, New York, 2018

18. C.Y. Wang, J. Shi, W.Q. Cao, H. Dong, Mater. Sci. Eng. A 527 (2010) 3442-3449

19. A. Ebrahimian, S.S. GhasemiBanadkouki, Mater. Sci. Eng. A 677 (2016) 281-289

20. C. Wells, W. Batz, R.F. Mehl, JOM 2 (1950) 553-560

21. T. Svec, M. Merklein, Proceedings of the 7 th Erlanger Workshop Warmblechumformung, Erlangen, 2012, pp. 55-70
22. D. Liedtke, Merkblatt 452 "Einsatzhärten", StahlInformations-Zentrum, Düsseldorf, 2008

23. J.I. Goldstein, A.E. Moren, Metall. Trans. A 9 (1978) $1515-1525$

24. J. Gegner, A. Vasilyev, P.J. Wilbrandt, M. Kaffenberger, Proceedings of the 7th International Conference on Mathematical Modeling and Computer Simulation of Material Technologies, Ariel, 2012, pp. 259-285

25. B. Edenhofer, D. Joritz, M. Rink, K. Voges, Thermochemical Surface Engineering of Steels, in: E.J. Mittemeijer, M. A.J. Somers (Eds.), Woodhead Publishing, Cambridge, 2015)

26. J.J. Friel, X-ray and image analysis in electron microscopy, Princeton Gamma-Tech, Princeton, 1994

27. P.-J. Wilbrandt, J. Gegner, R. Kirchheim, Physics meets industry, in: J. Gegner, F. Haider, Proceedings of the 1st DPG Symposium, Regensburg, 2007, Expert Verlag, Germany, pp. 58-74

Cite this article as: Alexander Horn, Marion Merklein, Investigation of diffusion behavior of carburized sheet metal in hot stamping, Manufacturing Rev. 6, 16 (2019) 